\title{
Connecting Youth Receiving SSI to Transition Services: The Role and Perspective of Family Advocates
}

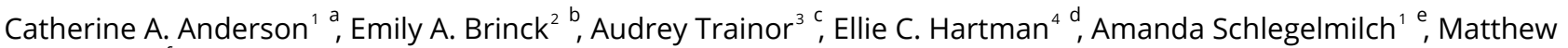 \\ Roskowski $^{1}$ \\ 1 University of Wisconsin-Stout, ${ }^{2}$ University of North Dakota, ${ }^{3}$ New York University, ${ }^{4}$ Wisconsin Department of Workforce Development \\ Keywords: youth, vocational rehabilitation, family advocates \\ https://doi.org/10.52017/001c.24416
}

\section{Rehabilitation Counselors and Educators Journal}

Vol. 10, Issue 1, 2021

\begin{abstract}
Students and youth receiving Supplemental Security Income (SSI) often encounter challenges during the transition process due to the added complexities of family poverty, health conditions, and systemic inequities (Hemmeter, 2014; Honeycutt \& Livermore, 2018; Wittenburg \& Loprest, 2007). Through the multiple phases of recruitment and enrollment in the Wisconsin Promoting the Readiness of Minors in Supplemental Security Income (WI PROMISE) demonstration project, youth and families were more likely to engage with those with similar lived experiences in their home communities. As a result, integrating a new position of family advocate or navigator into the transition process for youth receiving SSI benefits may be beneficial in helping youth and their families successfully navigate the transition process and increase engagement in vocational rehabilitation (VR) services. This study investigated WI PROMISE family advocates' views of their supportive role, families' strengths and needs, and challenges that emerged as they supported families during the transition process. Results indicated three key themes: (a) the importance of building trust and raising expectations; (b) effective partnership, accountability, and teamwork across systems; and (c) peer-based roles as coach, mentor, problem solver, and navigator.
\end{abstract}

Employment is an important factor in enhancing individual and household financial empowerment and well-being, as well as building social capital, self-efficacy, and inclusion in the community for individuals with disabilities (Brucker, 2015; Nye-Lengerman \& Nord, 2016; Potts, 2005; Regenold et al., 1999). Competitive employment is beneficial, and engaging youth with disabilities in work during high school is one of the key predictors increasing the likelihood of postschool employment success into adulthood (E. W. Carter et al., 2010, 2012). Yet according to the Bureau of Labor Statistics, only $18.6 \%$ of transition-aged youth with disabilities are employed when compared with $64.8 \%$ of transition-aged youth without disabilities (U.S. Department of Labor, Bureau of Labor Statistics, 2018). This notable disparity indicates an ongoing need to more effectively identify and reduce employment barriers for youth with disabilities, with a particular emphasis on using practices that meet individuals' and families' needs and highlight their strengths.
Making decisions about the future, including independent living, employment and careers, postsecondary education or training options, and navigating the various educational and adult service systems can be overwhelming (Bagatell et al., 2017). The added complexities of chronic poverty, health conditions, and systemic inequities can be particularly challenging for youth receiving Supplemental Security Income (SSI; Hemmeter, 2014; Honeycutt \& Livermore, 2018; Wittenburg \& Loprest, 2007). While these youth may be eligible for additional supports to help promote early work experiences and postsecondary opportunities, the services often go underutilized because many are not aware of the public vocational rehabilitation (VR) program, and services vary considerably from state to state (Honeycutt et al., 2015). Recent research found that less than $1 \%$ of transition-aged youth receiving SSI in the sample had an open VR case despite being eligible for the program, and only $1.5 \%$ of eligible youth were utilizing the Student Earned Income Exclusion (SEIE), a key work incentive

\footnotetext{
a andersoncay@uwstout.edu

b emily.brinck@und.edu

c aat8@nyu.edu

d ellie2.hartman@dwd.wisconsin.gov

e mandaschlegs@gmail.com

f roskowskim@uwstout.edu
} 
available to students receiving SSI benefits (U.S. Government Accountability Office, 2017).

\section{Poverty and Trauma Informed Care}

A growing body of research also demonstrates the importance of understanding trauma influences on engagement and outcomes within public programs, and advocates for integration of trauma-informed frameworks within disability, counseling, and human services systems (Bulanda \& Byro Johnson, 2016; Goad, 2021; Keesler, 2014, 2020; Sweeney et al., 2018). Trauma is associated with poverty, and a chronic lack of resources over time can increase stress and anxiety, impact employment and work performance, and intersect with related social determinants of health (American Psychological Association, 2017; Barrow et al., 2019; Nijdam et al., 2018). Using a trauma-informed framework grounded in key principles, including use of peer supports, is critical for enhancing participant engagement and positive outcomes across various public service systems (Bowen \& Murshid, 2016; Sweeney et al., 2018).

\section{Family Advocates}

Family advocates, defined as individuals with lived experience similar to the population receiving services, can play a key role in trauma-informed practice as guides to help youth and families navigate complex systems. In the Wisconsin Promoting the Readiness of Minors in Supplemental Security Income (WI PROMISE) demonstration project, all family advocates were parents of youth with disabilities and lived in the same region or community and sometimes shared the same race or ethnicity as project participants (Hartman et al., 2019).

This peer-based support may be instrumental in enhancing the development of good working alliances, an evidence-based construct for increasing successful employment outcomes, between youth receiving SSI, their families, and VR (Iwanaga et al., 2019). Maintaining an effective working alliance can be challenging for VR counselors to accomplish independently due to the inherent time constraints involved with managing large caseloads and can negatively impact the nature of the relationship between consumers and counselors (Kierpiec et al., 2010). Despite reduced caseloads during the demonstration project, WI PROMISE counselors, who were all rehabilitation counselors employed by the state VR agency, noted that the additional complexities faced by families experiencing poverty required significantly more time to address. An example included providing guidance in meeting basic needs related to housing insecurity and transportation, with immediate issues frequently taking precedence over participation in employment-focused training.

The use of peer-based family support has demonstrated efficacy in related professions including health care and public health programs. As an example, the integration of family navigators for intensive care unit (ICU) patients with cognitive impairments and their families enhanced support, and was received positively by patients, family members, and medical professionals (Torke et al., 2016). A similar study used patient navigators with people at risk of developing type 2 diabetes and found that those who had a nav- igator improved self-efficacy in health managing. This program also received overwhelmingly positive feedback from both patients and providers (Loskutova et al., 2016).

\section{Wisconsin PROMISE}

WI PROMISE, an experimental demonstration project, aimed to explore whether the implementation of a cadre of defined evidence-informed services improved employment and postsecondary outcomes for youth age 14-16 years receiving SSI benefits (Hartman et al., 2019; Honeycutt \& Livermore, 2018). The five-year demonstration consisted of participant recruitment, enrollment, and randomization into treatment and control groups, which was immediately followed by at least two years of training, career, and economic self-sufficiency support services for participating treatment group youth and their family members. During the 24-month enrollment period, the evaluation team and project leadership noted that participants were substantially more likely to enroll and engage when information about the project was shared by a peer with similar lived experience. Recruited treatment participants were concurrently enrolled in both WI VR and PROMISE services. WI VR dedicated staff provided both PROMISE and VR case management and counseling. In the third year of the project, WI PROMISE opted to employ family peers as advocates to enhance participant engagement and more effectively meet the complex needs of low-income youth and families. The new intermediary "Family Advocate" positions were developed to work with families by providing flexibility in meeting when and where it was most convenient for participants. They also provided supportive and individualized assistance in completing specific training, assisted families with administrative paperwork and forms across various programs, and provided support regarding school Individualized Education Program (IEP) and other important meetings. Eleven individuals were hired statewide as family advocates to assist participants, with whom they shared common disability-related experiences, navigate and engage with transition services and supports.

Notably, prior research confirmed that employment rates were significantly higher when participating youth and families met with family advocates (Hartman et al., 2019). WI PROMISE VR counselors, as well as youth and family participants, identified family advocates as an important addition to the project. To better understand this additional function, we conducted a focus group with the family advocates to learn about their experience and perspective regarding how their role helped influence positive participant engagement and employment outcomes. Given the earlier positive outcomes, this study then sought to better understand the perspective and experience of family advocates by addressing the following research questions:

1. What strategies were helpful in facilitating youth and family engagement in employment-focused transition services?

2. How did the family advocate role help facilitate effective working relationships between participant families and VR?

3. What were the most important roles and duties of the family advocates? 
Table 1. Focus Group Participant Characteristics

\begin{tabular}{|c|c|c|c|c|}
\hline Pseudonym & Race/Ethnicity & Sex/Gender & Age & Education \\
\hline Farrin & African American & Female & 43 & High School \\
\hline Glenn & Hispanic & Female & 26 & High School \\
\hline Kacey & White & Male & 46 & College \\
\hline Kara & African American & Female & 35 & High School \\
\hline Lane & White & Female & 40 & College \\
\hline Monique & African American & Female & 40 & College \\
\hline Sage & African American & Female & 57 & High School \\
\hline Skylar & White & Female & 55 & High School \\
\hline Sophie & White & Female & 43 & College \\
\hline
\end{tabular}

\section{Method}

\section{Participants}

A focus group consisting of nine family advocates employed through the WI PROMISE project was conducted. Family advocates were hired based on their personal experience as parents of children with disabilities. Throughout the demonstration project, over 900 youth and families were referred to family advocates by their WI PROMISE VR counselor, with 594 participant families opting to use the auxiliary service. Once referred, a family advocate residing within, or in close proximity to, the family's home community was assigned. In addition to a shared community affiliation and experiences parenting a child with a disability, the majority of advocates also shared similar racial, socioeconomic, and language backgrounds with their assigned families. Table 1 provides an overview of participant characteristics.

\section{Data Collection and Analysis}

The 90-minute focus group used a series of semi-structured interview questions to guide the discussion. One member of the research team served as group moderator and ensured that each participant had an opportunity to respond and contribute to the questions posed. Three additional members of the research team served in supportive observational note-taking roles. The interview was conducted during a regularly scheduled monthly meeting of family advocates, however supervisors were not included in the focus group interview in an effort to foster open and authentic conversation. All nine family advocates who attended the monthly meeting volunteered to participate in the focus group interview; the remaining two did not attend the meeting due to scheduling conflicts. Written consent was gathered from participants and everyone was reminded they could leave and/or skip any questions they did not elect to answer. Participants were also reminded that the contents of the focus group interview were considered private, and everyone agreed not to share direct quotes and information outside the boundaries of the session.

Prior to the focus group, an interview guide and protocol were developed based on research questions and aspects of the family advocate role. Open-ended questions were used to facilitate a semi-structured, rich discussion of family advocates' roles and experiences working with youth and families through WI PROMISE. A complete interview protocol is available from the first author upon request. The interview session was digitally recorded, and the audio recording was subsequently transcribed. Researchers listened to the original recording, cleaned the transcripts for accuracy, and prepared the data for analysis, which included assigning all participants with a pseudonym. NVivo12 software was used to organize, code, and preliminarily identify themes within the qualitative data. The research team then used opencoding and inductive analysis methods to interpret meaning from the data, including multiple rounds of discussion to reach consensus (Gioia, 2021; Patton, 2015).

\section{Results}

Family advocates openly expressed their viewpoints regarding their own personal strengths and challenges, as well as those experienced by participants. They shared the importance of working as a team, supporting each other in their roles, and using their experiences to work through implementation issues as they arose. From their perspective, the family-centered approach offered by WI PROMISE was impactful in a positive way. Family advocates saw this as important in not only addressing disability, but also effective in addressing the compounding stressors and impacts of poverty and trauma. Lane shared, "I think the best thing with PROMISE is they did the whole family, because that whole poverty piece, there's a lot to [it]...”. Family advocates also underscored the strength, resiliency, and self-determination presented by WI PROMISE families, with Sophie noting:

I would just say overall, I have just been amazed at how some of these families have been to hell and back several times...And [they do] not allow other people to define what [their] future is going to be like. And that is, it's powerful, powerful beyond words. And [they are] not alone.

The results of this study are presented to illustrate (a) the importance of building trust and raising expectations; (b) effective partnership, accountability, and teamwork 
across systems; and (c) peer-based roles as coach, mentor, problem solver, and navigator.

\section{Building Trust and Raising Expectations}

Across families, advocates implemented trauma-informed practices, including flexible scheduling and communication, proactively reaching out to connect with youth and families, and ongoing promotion of high expectations around employment and transition services goal attainment. Family advocates reached out to participants at least every three weeks using a variety of communication strategies, including texting, instant messaging, emailing, and calling. Family advocates also assured flexibility in meeting times and locations, such as meeting during evenings and on weekends and allowing youth and families to pick their preferred meeting location to enhance engagement. Further, family advocates' emphasis on follow-through, including returning calls and completing agreed-upon tasks consistently and in a timely manner, was critical in building trust with families.

Several family advocates mentioned the importance of follow-through given that some participants were wary based on prior experiences, "So, I think...some of these people that the system had failed, or they felt the system had failed them, that we were able to re-engage some of these people's trust in us and then trust the system again.” Advocates noted that despite challenges and difficulties in life, a number of youth participants increased their employment opportunities and income, and successfully resolved transportation challenges. Skylar described the importance of encouraging and engaging participants experiencing complex life situations who were frequently in "survival mode" and trying to get by day to day:

Realizing that there's trauma in most of these families and realizing that just because your time is your time, it doesn't mean it's the right time for them...realizing they have this trauma and it may take them time to come through it and keep re-engaging with them, pushing back a little bit, but letting them know that you're there...A simple text, "Hi, how you doing?" A simple little card, "How you doing? Hope you're having a great day. I'm thinking about you." All that stuff means the world to these people because they know another system hasn't failed them, that you're still going to be there and you realize that just because you feel the time is right, doesn't mean it's right for them.

\section{Meeting Basic Needs}

In order to establish rapport and help facilitate engagement with WI PROMISE services and employment, several family advocates noted that they first had to help families meet basic needs. Many families enrolled in the program experienced housing instability, food insecurity, a lack of reliable transportation, and scarcity in other key resource domains. When considering the youth and families, Sophie shared:

When you talk about needs, I think like their basic needs as the parents, as the family, had to be taken care of before anything else, before they could even wrap their head around anything else. And I think that that is part of what we've all done is to have those conversations with and to tear down those barriers. And sometimes of course, just helping them communicate with the appropriate people.

To help youth and families successfully address their basic needs, it was integral for the family advocate to build trust within the relationship. Sage spoke to the importance of meeting the family where they are at before guiding them toward services and employment:

I do believe helping them with those other important issues, because you didn't have a place to stay or, or cold, and a lot of that stuff...was not on the agenda you know, we went as sequence of important to them. We conquered those things, then we were able to focus. Yeah. And then that ultimately you have to gain trust to lead them to a different way.

\section{Expectations and Goals}

Another important perspective identified was the need to manage and expand the expectations families held related to the potential outcomes regarding service participation and employment and help address fears and misinformation. Family advocates discussed the ways in which participants' expectations and hope about the future were positively impacted through their roles. Several methods and techniques were implemented to aid in this process, ranging from sharing lived experiences, troubleshooting, educating participants to help build competency in systems navigation, and helping participants overcome their fears and misperceptions. Family advocates were able to use their personal experience and stories to help participants move beyond their limited view of expected outcomes. Skylar highlighted the importance of being able to share and leverage her lived experience when engaging with participants:
I think a lot of the parents didn't think that they could go any further because they didn't know what they didn't know. So, a lot of times when we brought the re- sources to them or gave them case scenarios of, Hey, we know a family who had a child similar to yours or more cognitively delayed than yours, that type of, and look at where they are now, it is possible. Think more on the positive side than the negative side. But when you're in systems like that, in order to get benefits, that's nor- mally where you're drawn to is to think of all the neg- atives. So, to turn it around and start thinking of the positives, it's a whole different mindset that you have to get yourself into.

Another example came from Sophie sharing a personal experience about helping her siblings with disabilities overcome barriers and gain employment:

I think that those social stories to be able to say, from my experience...my brother with a disability and yes, he's, yes, he has a developmental disability. Yes, he's driving. Yes, he's working full-time. Really truly meant something to those families because they believed me because they knew that I was coming from a place of experience and that it truly made a huge difference. And I think we've had this discussion about our own experience, how that really impacted those things. 
Some family advocates discussed the influence of generational poverty, employing a "culture of poverty" view that connected unemployment to reliance on federal benefits as a primary income source. Monique expressed this point of view, stating,
A lot of people that's in low-income situations, they mainly felt like, it's like a generational agenda, to be generationally low income or you know, it's just, it's, in the mindset like I'm gonna get a check, you gonna get a check. We gonna get a check. This here is inher- ited behavior in that and that they felt like this was the only way that they could make it. So, if they get a job, they're not going to be able to get this check, but not really realizing that if this person getting job and then it will bring more income into the house then what you're getting out of a check. But the check was more secure. It was a secure thing to have. But having, being able to move them from that, for the young people was a big deal. Learning from the parents and the grandpar- ents and the people before them seeing that that's way that they were going. So, I think that was a big thing for me as well.

A fear of losing their benefits was identified by other family advocates, too. Family advocates frequently connected the families to a benefits specialist who could educate them on benefits and try to dispel their fears. Part of the family advocates' role was to educate families about their benefits and try to break down fears, anxiety, and myths about employment. One family advocate expressed that having available services, like benefits counseling, was helpful in moving youth and families closer to employment. Farrin stated:

And I think that being able to for us having, to readily access, to be able to say, Hey, we need these services like benefit analysis, to be able to bring people to sit down with them saying you can still get your check and then letting them know you're not going to be cut off. You can work. This is how much money you can make and letting them realize they can succeed. There are things out there that they can do with a disability. And still be able to work.

Kara shared that her youth and families started identifying meaningful goals and working through various barriers while simultaneously also increasing their income. She said, "like setting higher expectations for themselves...and be able to live what you know without the barriers like, or even just to be able to have a little more extra spending money." Family advocates noted that use of goal driven plans helped maintain a focus on employment while also helping families overcome barriers that impeded engagement in services. Kacey said:

...but how are we working towards and keeping that, you know, someone overseeing us and managing us to remind us of the things that, 'cause it's easy to get caught up in their stuff and forget the goal of employment, but having good supervisors. And then...having those meetings and making sure we stay that focused because you have, having that structure, having where we had people to answer to it, cause it's not like we're out there and just freelancing all over the place that there's structure built in and that we're meeting with someone that makes sure that we're, that we're staying focused on the, you know, that we, yes, we have to help families address these issues so they have employment goals, but making sure we get to those employment goals.

\section{Effective Partnership, Accountability, and Teamwork}

While family advocates shared a range of experiences in partnering with WI PROMISE VR counselors, schools, and service providers, one of the prominent themes involved approaching it as an effective partnership and teamwork. Many advocates spoke to the mutual accountability this type of relationship promoted, helping ensure that various members of a youth's team were completing agreed upon next steps. To help build this alliance, one geographic region arranged regular meetings between the WI PROMISE VR counselors and family advocates to actively review cases on which they were collaboratively working. Highlighting the importance of the establishing positive working relationships between advocates and WI PROMISE VR counselors, Kacey stated:

Yeah...the [WI PROMISE VR] counselors that were willing to do that and meet with us and bought into what we were doing. And I think, I think if you looked back and saw the families with the biggest gains, I bet if you dug into those cases, it would be where the family advocate was involved in. You had buy-in from the [WI PROMISE VR] counselor on the family advocate position.

As Skylar stated, part of this responsibility included holding providers accountable to ensure participants were receiving the services they needed:
We could definitely bridge the gap between them and a lot of the service providers because a lot of times they would call, couldn't get through or didn't know what we knew. We were kind of on the front end. Sometimes we knew things that they didn't know. So maybe we knew that person. Like in direct response, like [WI PROMISE VR], we would know that the person was out, or they are harder to reach and sometimes we would have to go through other methods to make sure they got back. But they knew if they told us that we would be there for them and we would follow it through to the end.

Beyond ensuring that participants' needs were met, family advocates served as a bridge between participants and WI PROMISE VR counselors, particularly when reengaging inactive cases or helping youth understand their working relationship with their counselor. Kacey spoke to both of these points when she stated:

Yeah, 'cause we could help them work through like the conflict resolution stuff with [WI PROMISE VR] where, where in the past, like if VR lets down a client they're just going to walk away but they come back to us and say [WI PROMISE VR] let us down. Then we can say well this is how you appeal that decision. This is who you go to. And you know we had some direct lines, but then we also could teach them that in you know how to do it when we weren't there. This is how you appeal 
that decision. This is how like if you really just can't work with your [WI PROMISE VR] counselor, this is how you change it. But as far as working together, the other thing is I think that the agencies like the [WI PROMISE VR] counselors that have bought into our role and then reached out to us to find out some of that back information because they didn't have as much time.

The WI PROMISE program offered various services and training to participants. As such, participants were often required to meet and interact with a wide range of professionals to complete different activities. WI PROMISE VR counselors connected youth and families to a variety of services provided by different service providers. Despite best efforts coordinating services, navigation of service systems could be complicated and overwhelming. Family advocates provided life experience and a peer perspective to help bridge or liaison between participants and service providers when needed, helping support smooth transitions and navigation of the complex network of services and providers. Acting as a link between participants and service providers also allowed family advocates to help demystify the process and facilitate an understanding of the various activities involved. Sage touched on helping families navigate a broad web of providers when she stated, "Positions weren't explained to our parents as to who did what...we wouldn't even know who they were and if they're asking questions, we want to direct them to the proper person." Sage and other family advocates found it useful to provide families with a list of their team members, including which services they provided as well as their contact information.

Another strategy implemented by Glenn involved including all members of a participant's team in email communications to help clearly delineate roles, responsibilities, and a path forward for the youth.

I think the strategy that worked for me is that I brought [WI PROMISE] VR attention to see can we have the service providers that are helping a family. So, we had a benefit specialist, a job coach, a financial coach just so the family can see the faces. And then after the meeting I send out an email. Like this is what we talked about and our roles of what each were going to do. I mean the role we're each gonna take to follow up with the family to, but the family got to see each phase...I think was a good strategy that helped a lot.

Focus group participants shared mixed experiences in working with youth, families, and local schools. WI PROMISE emphasized PROMISE VR and school collaboration in implementing postsecondary transition plans and services. To aid participant family engagement with schools, WI PROMISE collaborated with Wisconsin Family Assistance Center for Education, Training, and Support (WI-FACETS) and Wisconsin Statewide Parent Educator Initiative (WSPEI). These collaborations led to improved employment outcomes for WI PROMISE participants (Hartman et al., 2019). Still, even with these collaborations, some youth and families still struggled developing effective partnerships with the school, and had questions regarding academic, behavior, and IEP processes that best aid the transition from school to career. Several of the family advocates indicated they struggled to navigate the best ways to help mitigate challenges regarding school collaboration, coordination, and the IEP process. One participant stated, "I had a client who only wants to meet at school but, I couldn't go into the school", while another participant stated:
So, the IEP thing, so that something that we thought we'd be able to, because according to the rules of the IEP, the family's allowed to bring whoever they want. But then we were told we couldn't go. And so, I think there was some misconception about the, the name ad- vocate, I think that has a, it has a connotation through- out the state that, you know, and I don't, it doesn't matter whether or not it's fair, it's there. But I think, 'cause we would talk with families about how to, in a lot of the IEP is what setting up their goals for the future. So, if they don't feel like they're part of that team and if they don't feel like they have people that they want to support them there, it's, it's hurting the transition. And so, I think that was important.

Other family advocates did not have challenges accessing the schools,

\begin{abstract}
....But we were able to go to the school in [City 1] and [City 2] that was the best thing we were able to do once we got [City 1] and [City 2] together 'cause they let them be there. But we were able to work with the counselors in the school and the transition coordinators and when we were going in asking questions about like, well, they gonna graduate. Then they're getting out of school at 10 o'clock. Wow. What are you all doing for transitioning to help this person go to college or help this person get job skills because the school pays for them so that they can have these skills when they are not worked too much. I have time on my hands. We were able to get in and do that and able to get in to do some of the selfadvocacy and family advocacy training and they let us come in during lunch break. That was a big thing for us.
\end{abstract}

\section{Family Advocate as Coach, Problem Solver, and Navigator}

Several family advocates considered their role as coach to be a top priority. In addition to informing families about various services, they felt strongly about presenting information in a manner that encouraged participants to selfadvocate and navigate systems independently into the future. Family advocates served to educate participants about employment possibilities and had time to sit down with the families and explain how benefits worked. This in turn, was perceived to help increase participants' self-confidence in pursuing employment opportunities, dispel myths, and explore options for future economic mobility. Farrin shared:
...to be able to sit down with them saying you can still get your check and then letting them know you're not going to be cut off. You can work. This is how much money you can make and letting them realize they can succeed. There are things out there that they can do with a disability. And still be able to work. And some of them are like, “I can work?” They were told they could never work; they could make money and then it's a rev- elation to them.

Family advocates also taught youth and families how to effectively work with VR so that when the PROMISE demon- 
stration project ended, participants would have the skills and knowledge to effectively continue to advocate and manage working relationships with VR on their own. Several family advocates also stated that engaging youth and families in training and providing mentoring were key parts of their role. Monique commented that family advocates were key in helping their youth and families connect to critical services. She stated:

And so, for me, I think we started out, we started out as trying to help them with certain things....and we ended up being the connection between the more needed services that they really, really needed. And we were the people. I think we became like we were the people that put the fires out.

Several family advocates conveyed their role as being a mentor to help empower participants, particularly those facing barriers or lacking prior experience with providers and systems. Sophie's quote helps to illustrate this further,

And also, as a mentor. And then I always say that I feel like I've been a part cheerleader as well. When they have experienced situations with other service providers that have left them demoralized and frustrated it often, I felt like I've helped empower them and build their spirits up so that they can continue to keep accessing the supports and services that are beneficial for them.

Family advocates provided guidance and encouraged youth and families to keep engaging in programs, services, and trainings even if they had been disappointed in the past. Kacey remarked:

And again, like you said, where that mentorship role, where we helped and depending on where the family was, helped them initially and then transferred the work back over to them. So that they, the time needs to make the contacts on their own and thinking about the way systems are siloed and helping them figure out how to connect it, but walking them through it because they so often they'd, they were let down by systems and shutdown and they needed someone to walk them through to help build confidence.

While many family advocates felt like they provided lived experience and emotional support, others saw their role as a versatile supporter with the ability to address complex and diverse needs. Sophie stated:

But I think what became a bigger part of our role was to just help them problem solve, you know, because a lot of these families came with issues that weren't necessarily being handled, whether it be depending on the area housing or food or things like that. And then just helping them problem solve so that way they could focus on finding jobs and doing some other stuff. So, I think...we ended up becoming just more of a catchall and then helping them look for resources.

Family advocates often found that their main role was to help participants navigate the dense web of contacts, services, and providers. Lane shared, "I think kind of system navigations...and helping them trust the systems with, you know, besides everything else that everybody else said. I had many people who didn't know about certain programs," and, "...That we could definitely bridge the gap between them and a lot of the service providers because a lot of times they would call, couldn't get through or didn't know what we knew. We were kind of on the front end.” Another family advocate expressed a similar view in regard to families from historically marginalized groups who had been let down by systems in the past that had resulted in broken trust. Kacey said:

But as I think you bring up a great point about the difference in the underserved communities and in the black and brown families were that many of our families felt shut down by the system. Especially families in minority [communities] where I work in the, my part of the state, there's a lot of Native communities that felt cut off and felt like the systems weren't available to them and, and helping them re-engage in the system, cause it's a problem across all of them. But it was a marked problem when you went in minority families.

Several family advocates discussed the resiliency they saw in their youth and families despite experiencing being faced with numerous barriers. Lane commented, "Yeah, I think for the strength and resiliency is, but get back up after they hit those barriers and then continue to get back up after they hit barrier after barrier after barrier. Never give up." Another family advocate concurred and discussed a specific family's employment and involvement in the program even when they were confronted with challenges along the way:

They had all kinds of barriers. They had jobs that didn't
work out. They re-engaged and now, because [we] be-
lieved in them, they stuck with the system. We had a
family where everybody was on assistance and now all
of them are employed and mom was going to college.

\section{Future Implications for Practice and Research}

This study sought to better understand perspectives shared by family advocates based on their work with youth and families during the WI PROMISE project. Family advocates' perspectives inform the development and success of programs assisting youth with disabilities transition to positive postsecondary outcomes. Challenges related to generational poverty were consistently noted throughout the conversation, with family advocates sharing that many families believe the system had failed them. Many public programs were designed using white, middle-class frameworks, which may not consider hardships and adversity experienced by those from diverse backgrounds, including those with significantly limited resources. For those experiencing both disability and poverty, and working with multiple programs and providers, it can take a considerable amount of time and energy to effectively navigate these systems. Additional research about the role of family advocates working with families and individuals with disabilities can help pinpoint how shared life experiences may foster trust and communication. Important questions related to where these positions reside organizationally, and clearly understanding and defining role and function, will guide further development and refinement of the model. Furthermore, research to better understand the nuances of recruiting and prepar- 
ing individuals with firsthand experience to serve as family advocates will be important in developing strategies to enhance efficiency, effectiveness, and efficacy throughout the implementation process.

A growing body of empirical knowledge underscores the importance of integrating trauma-informed approaches into health and human services programs, including building trusting relationships, offering flexible service delivery formats, and working to empower participants, mirrors the input and recommendations provided by family advocates (P. Carter \& Blanch, 2019; O’Sullivan et al., 2019). Given that SSI is a needs-based program for those with limited income and assets, youth and families receiving this benefit may be more likely to experience the compounding influences of trauma. Therefore, integrating peer-based traumainformed approaches, such as family advocates or similar coaching and navigation roles into VR and related employment programs, offers considerable opportunity to increase engagement and employment outcomes with this population.
While this study was conducted prior to COVID-19, the youth and families served by many of the family advocates represent communities and populations disproportionately impacted by the pandemic (Collin-Vézina et al., 2020; Lund, 2020; Webb Hooper et al., 2020). Therefore, the need for trauma-informed approaches to employment and transition services for youth and families receiving SSI may be even greater moving forward. Given the demonstrated efficacy of family advocates in Wisconsin (Hartman et al., 2019, 2021), coupled with valuable perspectives from individuals having served in the role, the integration of similar peer-based positions to help low-income youth with disabilities and their families navigate the transition and employment process is recommended. Testing this model in additional states collaboratively across systems including VR, education, health and human services, and community service providers offers a sound opportunity to better serve this population, enhance engagement and success in disability employment programs, and meaningfully change the future career and life trajectory for youth with disabilities. 


\section{REFERENCES}

American Psychological Association. (2017). Stress and health disparities: Contexts, mechanisms, and interventions among racial/ethnic minority and lowsocioeconomic status populations. http://www.apa.org/ pi/health-disparities/resources/stress-report.aspx

Bagatell, N., Chan, D., Rauch, K. K., \& Thorpe, D. (2017). “Thrust into adulthood": Transition experiences of young adults with cerebral palsy. Disability and Health Journal, 10(1), 80-86. https://do i.org/10.1016/j.dhjo.2016.09.008

Barrow, J., Wasik, S., Corry, L. B., \& Gobble, C. A. (2019). Trauma-informed career counseling: Identifying and advocating for the vocational needs of human services clients and professionals. Journal of Human Services, 39(1), 97-110.

Bowen, E. A., \& Murshid, N. S. (2016). Trauma-informed social policy: A conceptual framework for policy analysis and advocacy. American Journal of Public Health, 106(2), 223-229. https://doi.org/10.2105/ajp h.2015.302970

Brucker, D. L. (2015). Social capital, employment and labor force participation among persons with disabilities. Journal of Vocational Rehabilitation, 43(1), 17-31. https://doi.org/10.3233//VR-150751

Bulanda, J., \& Byro Johnson, T. (2016). A traumainformed model for empowerment programs targeting vulnerable youth. Child and Adolescent Social Work Journal, 33(4), 303-312. https://doi.org/1 0.1007/s10560-015-0427-z

Carter, E. W., Austin, D., \& Trainor, A. A. (2012). Predictors of postschool employment outcomes for young adults with severe disabilities. Journal of Disability Policy Studies, 23(1), 50-63. https://doi.org/ 10.1177/1044207311414680

Carter, E. W., Ditchman, N., Sun, Y., Trainor, A. A., Swedeen, B., \& Owens, L. (2010). Summer employment and community experiences of transition-age youth with severe disabilities. Exceptional Children, 76(2), 194-212. https://doi.org/1 $\underline{0.1177 / 001440291007600204}$

Carter, P., \& Blanch, A. (2019). A trauma lens for systems change. Stanford Social Innovation Review, 17(3), 48-54. https://static1.squarespace.com/static/5 afd9cd9365f026d73136d45/t/5e59a09d0054c8536148c f49/1582932126186/Stanford+Review.pdf

Collin-Vézina, D., Brend, D., \& Beeman, I. (2020). When it counts the most: Trauma-informed care and the COVID-19 global pandemic. Developmental Child Welfare, 2(3), 172-179. https://doi.org/10.1177/25161 03220942530

Gioia, D. (2021). A systematic methodology for doing qualitative research. The Journal of Applied Behavioral Science, 57(1), 20-29. https://doi.org/10.1177/002188 $\underline{6320982715}$
Goad, E. (2021). Working alongside people with intellectual disabilities who have had difficult experiences: Reflections on trauma-informed care within a service context. Journal of Intellectual Disabilities. https://doi.org/10.1177/174462952098771 $\underline{7}$

Hartman, E. C., Jones, W., Kesselmayer, R. F., Brinck, E. A., Trainor, A. A., Reinhard, A., Fuller, R. K., Schlegelmilch, A., \& Anderson, C. A. (2021). Demographic and transition service predictors of employment outcomes for youth receiving Supplemental Security Income. Career Development and Transition for Exceptional Individuals, 44(2), 97-109. https://doi.org/10.1177/2165143420984797

Hartman, E. C., Schlegelmilch, A., Roskowski, M., Anderson, C. A., \& Tansey, T. N. (2019). Early findings from the Wisconsin PROMISE project: Implications for policy and practice. Journal of Vocational Rehabilitation, 51(2), 167-181. https://do i.org/10.3233/IVR-191036

Hemmeter, J. (2014). Earnings and disability program participation of youth transition demonstration participants after 24 months. Social Security Bulletin, 74(1), 1-25.

Honeycutt, T., \& Livermore, G. (2018). Promoting readiness of minors in supplemental security income (PROMISE): The role of PROMISE in the landscape of federal programs targeting youth with disabilities. Mathematica Policy Research. https://www.mathemati ca.org/our-publications-and-findings/projects/evalua te-the-promoting-readiness-of-minors-in-supplemen tal-security-income-promise-grants

Honeycutt, T., Thompkins, A., Bardos, M., \& Stern, S. (2015). State differences in the vocational rehabilitation experiences of transition-age youth with disabilities. Journal of Vocational Rehabilitation, 42(1), 17-30. https://doi.org/10.3233/IVR-140721

Iwanaga, K., Chan, F., Tansey, T. N., Strauser, D., Ritter, E., Bishop, M., \& Brooks, J. (2019). Working alliance and stages of change for employment: The intermediary role of autonomous motivation, outcome expectancy and vocational rehabilitation engagement. Journal of Occupational Rehabilitation, 29(2), 315-324. https://doi.org/10.1007/s10926-018-9 787-5

Keesler, J. M. (2014). A call for the integration of trauma-informed care among intellectual and developmental disability organizations. Journal of Policy and Practice in Intellectual Disabilities, 11(1), 34-42. https://doi.org/10.1111/jppi.12071

Keesler, J. M. (2020). From the DSP perspective: Exploring the use of practices that align with traumainformed care in organizations serving people with intellectual and developmental Disabilities. Intellectual and Developmental Disabilities, 58(3), 208-220. https://doi.org/10.1352/1934-9556-58.3.208 
Kierpiec, K. M., Philips, B. N., \& Kosciulek, J. F. (2010). Vocational rehabilitation caseload size and the working alliance: Implications for rehabilitation administrators. Journal of Rehabilitation Administration, 34(1), 5-14.

Loskutova, N. Y., Tsai, A. G., Fisher, E. B., LaCruz, D. M., Cherrington, A. L., Harrington, T. M., Turner, T. J., \& Pace, W. D. (2016). Patient navigators connecting patients to community resources to improve diabetes outcomes. Journal of the American Board of Family Medicine, 29(1), 78-89. https://doi.org/10.3122/jabf $\underline{\mathrm{m} .2016 .01 .150048}$

Lund, E. M. (2020). Even more to handle: Additional sources of stress and trauma for clients from marginalized racial and ethnic groups in the United States during the COVID-19 pandemic. Counselling Psychology Quarterly, 1-10. https://doi.org/10.1080/0 $\underline{9515070.2020 .1766420}$

Nijdam, M. J., van der Meer, C. A. I., van Zuiden, M., Dashtgard, P., Medema, D., Qing, Y., Zhutovsky, P., Bakker, A., \& Olff, M. (2018). Turning wounds into wisdom: Posttraumatic growth over the course of two types of trauma-focused psychotherapy in patients with PTSD. Journal of Affective Disorders, 227, 424-431. https://doi.org/10.1016/j.jad.2017.11.031

Nye-Lengerman, K., \& Nord, D. (2016). Changing the message: Employment as a means out of poverty. Journal of Vocational Rehabilitation, 44(3), 243-247. ht tps://doi.org/10.3233/IVR-160794

O’Sullivan, D., Watts, J. R., \& Strauser, D. R. (2019). Trauma-sensitive rehabilitation counseling: Paradigms and principles. Journal of Vocational Rehabilitation, 51(3), 299-312. https://doi.org/10.323 3/IVR-191047

Patton, M. (2015). Qualitative Research and Evaluation Methods (4th ed.). Sage Publications.

Potts, B. (2005). Disability and employment: Considering the importance of social capital. Journal of Rehabilitation, 71(3), 20-25.
Regenold, M., Sherman, M. F., \& Fenzel, M. (1999). Getting back to work: Self-efficacy as a predictor of employment outcome. Psychiatric Rehabilitation Journal, 22(4), 361-367. https://doi.org/10.1037/h009 $\underline{5214}$

Sweeney, A., Filson, B., Kennedy, A., Collinson, L., \& Gillard, S. (2018). A paradigm shift: Relationships in trauma-informed mental health services. BJPsych Advances, 24(5), 319-333. https://doi.org/10.1192/bj a.2018.29

Torke, A. M., Wocial, L. D., Johns, S. A., Sachs, G. A., Callahan, C. M., Bosslet, G. T., Slaven, J. E., Perkins, S. M., Hickman, S. E., Montz, K., \& Burke, E. S. (2016). The family navigator: A pilot intervention to support intensive care unit family surrogates. American Journal of Critical Care, 25(6), 498-507. http s://doi.org/10.4037/ajcc2016730

U.S. Department of Labor, Bureau of Labor Statistics. (2018). Labor force statistics from the current population survey. https://data.bls.gov/pdq/SurveyOut putServlet

U.S. Government Accountability Office. (2017). SSA could strengthen its efforts to encourage employment for transition-age youth. https://www.gao.gov/assets/690/ 684636.pdf

Webb Hooper, M., Nápoles, A. M., \& Pérez-Stable, E. J. (2020). COVID-19 and racial/ethnic disparities. JAMA, 323(24), 2466-2467. https://doi.org/10.1001/jama.202 $\underline{0.8598}$

Wittenburg, D. C., \& Loprest, P. J. (2007). Early transition experiences of transition-age child SSI recipients: New evidence from the national survey of children and families. Journal of Disability Policy Studies, 18(3), 176-187. https://doi.org/10.1177/10442 $\underline{073070180030601}$ 